\title{
RECICLAGEM ARTESANAL COM GARRAFA PET
}

\author{
Suzana Freitas Kelling Scherer ${ }^{1}$, Dionísio Link ${ }^{2}$ \\ ${ }^{1}$ Acadêmica da Especialização em Educação Ambiental da UFSM \\ ${ }^{2}$ Professor orientador da UFSM
}

\section{RESUMO}

Este trabalho reúne histórias criadas através de personagens com a garrafa pet de forma artesanal desenvolvidas no Colégio Madre Júlia (São Sepé, RS) com alunos da quarta série do ensino fundamental. Foi desenvolvida uma metodologia de trabalho que utiliza a dinâmica artística da construção do personagem da história com a garrafa pet, como introdução de ajudar e ver os problemas ambientais. Os textos trabalhados antes foram ferramentas para mostrar, o problema do lixo, o lixo que não é lixo, usar sim - mas com cuidado, portando através das leituras dos textos sentiram a importância da boa relação entre os homens e entre homem-natureza, sensibilizando as crianças para a realidade do meio em que vivem. No projeto trabalharam os Criadores de Histórias, que através de suas produções literárias, estimularam a percepção dos colegas, e, desta forma, foi possível a discussão das histórias em aula, o que, somado à criatividade das crianças, resultou em um livro de histórias "Vida da Garrafa Pet". Pode-se observar que através das histórias criadas pelos alunos, houve a possibilidade de sensibilizar as outras crianças para a realidade em que estão inseridas e, desta forma, o livro serviu de instrumento de informação e transformação, como forma lúdica.

Palavras-chave: reciclagem, garrafa pet, educação ambiental.

\section{INTRODUÇÃO}

A questão ambiental e a educação têm sido um dos temas discutidos nas agendas internacionais, principalmente, "Após a reunião do Clube de Roma em 1968 e a Conferência de Estocolmo em 1972." (REIGOTA, 1995, p. 9).

A Declaração de Estocolmo sobre Meio Ambiente (1972), em seu Princípio 19, prevê que

É indispensável um trabalho de educação em questões ambientais, visando tanto as gerações jovens como os adultos, dispensando a devida atenção ao setor das populações menos privilegiadas, para assentar as bases de uma opinião pública bem informada e de uma conduta responsável dos indivíduos, das empresas e das comunidades, inspirada no sentido de sua responsabilidade, relativamente à proteção e melhoramento do meio ambiente em toda a sua dimensão humana. 
No Brasil, a educação é assegurada pela Constituição Federal de 1988, em seu artigo 205, que estabelece que "A educação, direito de todos e dever do Estado e da família, será promovida e incentivada com a elaboração da sociedade, visando ao pleno desenvolvimento da pessoa, seu preparo para o exercício da cidadania e sua qualificação para o trabalho." Ademais, incumbe ao Poder Público "promover a educação ambiental em todos os níveis de ensino e a conscientização pública para a preservação do meio ambiente." (Artigo 225, VI).

Vale lembrar que a Lei Federal n. 6.938, de 31 de agosto de 1981, que dispõe sobre a política nacional do Meio Ambiente, objetiva:

\begin{abstract}
a preservação, melhoria e recuperação da qualidade ambiental propícia à vida,visando assegurar, no País, condições ao desenvolvimento sócio-econômico, aos interesses da segurança nacional e à proteção da dignidade da vida humana, atendidos os seguintes princípios: (...) $X$ - educação ambiental a todos os níveis de ensino, inclusive a educação da comunidade, objetivando capacitá-la para participação ativa na defesa do meio ambiente. (Artigo 2\%).
\end{abstract}

Baseado nos trechos citados acima é necessária a promoção integrada da educação ambiental como instrumento pedagógico, para a construção da cidadania, através da participação da comunidade escolar, especialmente alunos, na preservação do meio ambiente. $E$ é neste âmbito que será visado o trabalho lúdico da reciclagem da garrafa pet, para a sensibilização dos alunos de quarta série do ensino fundamental do Colégio Madre Júlia, de São Sepé - RS.

\title{
Problema
}

No Colégio Madre Júlia as crianças da quarta série do ensino fundamental são de classe média alta e nunca criaram o seu brinquedo.

\section{Objetivo Geral}

Sensibilizar o educando afim de que possa perceber-se integrante e agente mantenedor do meio ambiente, contribuindo decisivamente para melhoria na qualidade de vida do planeta.

\section{Objetivos Específicos:}

- Proporcionar e desenvolver no aluno a preservação do meio ambiente, por meio de atividades relacionadas ao desenvolvimento do próprio currículo de ensino.

- Focalizar a atenção dos alunos sobre a importância da natureza na vida do ser humano.

- Discutir os temas dos textos e fazer com que as crianças criem seus próprios personagens; 


\section{Justificativa:}

A questão ambiental não abrange somente a proteção do planeta, mas também a melhoria da qualidade de vida das pessoas. Falar em sala de aula de que é necessário e indispensável proteger a natureza e não praticar ações consequentes nesta direção é um contra-senso. Neste sentido, pretendeu-se sensibilizar os futuros cidadãos para a importância de conservar o meio ambiente, incentivando a coerência de comportamento, atitudes e habilidades condizentes à cidadania.

Os educadores necessitam conhecer como as crianças percebem o meio em que estão inseridas, a fim de despertá-los para a importância de preservá-lo à presente e às gerações futuras. Vale ressaltar que a percepção do ambiente é o primeiro passo para que as pessoas se conscientizem dos problemas sócio-ambientais, fazendo com que passem a realizar pequenas mudanças positivas em seu cotidiano, contribuindo para a busca da sustentabilidade.

\section{REFERENCIAL TEÓRICO}

\section{Educação Ambiental e a Escola}

Entende-se por educação ambiental os processos por meio dos quais o indivíduo e a coletividade constroem valores sociais, conhecimentos, habilidades, atitudes e competências voltadas para a conservação do meio ambiente, bem de uso comum do povo, essencial à sadia qualidade de vida e sua sustentabilidade.

Educação Ambiental é um processo de tomada de consciência política, institucional, e comunitária da realidade ambiental, do homem e da sociedade, para analisar, em conjunto com a comunidade (através de mecanismos formais e não formais), as melhores alternativas de proteção da natureza e do desenvolvimento sócio-econômico do homem e da sociedade (ROCHA, 1999).

Para que seja eficaz, um programa de educação para o meio ambiente deve desenvolver os conhecimentos, atividades e habilidades necessárias, para que a comunidade possa compreender o seu ambiente e desenvolver atividades que alterem os comportamentos das pessoas envolvidas no processo. O educando assume o papel de elemento central do processo de ensino/aprendizagem pretendido, participando ativamente no diagnóstico dos problemas ambientais e busca de soluções, sendo preparado como agente transformador, através do desenvolvimento de habilidades e formação de atitudes, através de uma conduta ética, condizentes ao exercício da cidadania. Devem-se buscar valores que conduzam a uma convivência harmoniosa com o ambiente e as demais espécies que habitam o planeta, auxiliando o aluno a analisar criticamente o princípio antropocêntrico, que tem levado à destruição inconseqüente dos recursos naturais e de várias espécies.

Portanto, a educação para o meio ambiente é um assunto que deve ser tratado de maneira integrada, visando à prática pedagógica e a representação social das pessoas envolvidas, colocando-os como participantes de um mesmo processo, na tentativa de solucionar os problemas ambientais. É importante que se encontrem novas formas de integração entre a sociedade e a natureza, uma nova dimensão que não seja apenas com a possibilidade de destruição de ecossistemas e deve-se estimular a ética no relacionamento econômico, político e social. Então pode-se subdividir em Educação Ambiental Formal, que é um processo 
institucionalizado que ocorre nas unidades de ensino e Educação Ambiental Informal que se caracteriza por sua realização fora da escola, envolvendo flexibilidade de métodos e de conteúdos e um público alvo muito variável em suas características (faixa etária, nível de escolaridade, nível de conhecimento da problemática ambiental, etc.).

Definida como uma dimensão dada ao conteúdo e à prática da educação, orientada para a resolução dos problemas concretos do meio ambiente através de enfoques interdisciplinares e de uma participação ativa e responsável de cada indivíduo e da coletividade. A Educação Ambiental caracteriza-se também, por incorporar dimensões não só políticas e institucionais, mas também, econômicas, culturais, ecológicas e éticas, o que significa que ao tratar de qualquer problema ambiental, devem-se considerar todas as dimensões. A preocupação com o desenvolvimento sustentável representa a possibilidade de garantir mudanças sociopolíticas que não comprometam os sistemas ecológicos e sociais que sustentam as comunidades (MEDINA, 1999).

A partir da Conferência Intergovernamental sobre Educação Ambiental realizada em Tbilisi (GEORGIA ex-URSS), em 1977, inicia-se um amplo processo em nível global orientado para criar as condições que formem uma nova consciência sobre o valor da natureza e para reorientar a produção de conhecimento baseada nos métodos da interdisciplinaridade e nos princípios da complexidade. Esse campo educativo tem sido fertilizado transversalmente, $\mathrm{e}$ isso tem possibilitado a realização de experiências concretas de educação ambiental de forma criativa e inovadora por diversos segmentos da população e em diversos níveis de formação.

O documento da Conferência Internacional sobre Meio Ambiente e Sociedade, Educação e Consciência Pública para a Sustentabilidade, realizada em Tessalônica (Grécia), chama a atenção para a necessidade de se articularem ações de educação ambiental baseadas nos conceitos de ética e sustentabilidade, identidade cultural e diversidade, mobilização e participação e práticas interdisciplinares.

O surgimento de um campo ambiental no Brasil está relacionado com os anos 70. A Educação Ambiental, por sua vez, é um fenômeno que começa a ganhar visibilidade na década seguinte, portanto apenas nos anos 80 que começa a configurar-se um espaço próprio dessa prática educativa. (CARVALHO, 2001)

A Lei Federal no 9.795, foi sancionada em 27 de abril de 1999, criando a Política Nacional de Educação Ambiental, dispondo sobre o inciso VI do artigo 225 da Constituição Federal, onde incumbe ao Poder Público promover a educação ambiental em todos os níveis de ensino e a conscientização pública para a preservação do meio ambiente (PNEA, 1999).

A educação ambiental aparece no cenário contemporâneo como exigência das profundas transformações ocorridas na sociedade moderna. Hoje, desenvolve-se uma sensibilidade para as questões ambientais e é reivindicação constante de propostas curriculares em diferentes níveis de ensino. Ela surge como uma das possíveis estratégias para o enfrentamento da crise civilizatória de dupla ordem, cultural e social. A Educação Ambiental é um dos eixos fundamentais para impulsionar os processos de prevenção da deterioração ambiental e de uma sociedade sustentável.

A relação entre meio ambiente e educação para a cidadania assume um papel cada vez mais desafiador, demandando a emergência de novos saberes para aprender processos sociais mais complexos e riscos ambientais que se intensificam. As políticas ambientais e os programas educativos relacionados à conscientização da crise ambiental demandam cada vez mais novos enfoques integradores de uma realidade contraditória e geradora de desigualdades, que transcendem a mera aplicação dos conhecimentos científicos e tecnológicos disponíveis. 
Segundo as Nações Unidas, a Educação Ambiental, deveria reorientar a educação para o desenvolvimento sustentável de forma a compatibilizar objetivos sociais de acesso às necessidades básicas; com objetivos ambientais de preservação da vitalidade e diversidade do planeta garantindo como direito aos cidadãos um ambiente ecologicamente saudável e com objetivos econômicos; aumentar a conscientização popular; considerar o analfabetismo ambiental e promover treinamento. (PELICIONI, 1998)

A educação ambiental tem como objetivo formar a consciência dos cidadãos e transformar-se em filosofia de vida de modo a levar a adoção de comportamentos ambientalmente adequados, investindo nos recursos e processos ecológicos do meio ambiente, assim transformando a teoria em prática. É necessário que o convívio do homem com o equilíbrio natural siga regras claras que considerem e respeitem a disponibilidade e a vulnerabilidade da natureza. Essas regras de convivência que definem os padrões comportamentais são as leis, que não são suficientes para a preservação da natureza, antes é preciso um processo de construção, baseado na Educação Ambiental como ponto de partida.

A Educação Ambiental por ser renovadora, induzir novas formas de conduta nos indivíduos e na sociedade, por lidar com as realidades locais, por adotar uma abordagem que considera todos os aspectos que compõem a questão ambiental - aspectos sociais, políticos, econômicos, culturais, éticos, ecológicos, científicos e tecnológicos - por ser catalisadora de uma educação para o exercício pleno e responsável de cidadania, pode e deve ser o agente otimizador de novos processos educativos que conduzam as pessoas por caminhos onde se vislumbre a possibilidade de mudanças e melhoria do seu ambiente total e da qualidade da sua experiência humana.

Não basta só tornar alunos "ecologicamente alfabetizados", é preciso fazê-los portadores de um conhecimento e de compromisso com a preservação da vida em todas as suas formas.

\section{O Problema do Lixo}

Os homens produzem resíduos líquidos, pastosos e sólidos (lixos) que contaminam a água, o ar, a vegetação, o solo e os animais.

Nos últimos anos o homem criou uma filosofia de praticidade e inventou o descartável. Produziu tanto lixo que parecia querer transformar a terra em um gigantesco aterro sanitário. Além disso, destruiu florestas, poluiu mares e rios e emitiu gases capazes de provocar alterações climáticas insuportáveis.

O lixo é apenas um dos muitos problemas, um incômodo indesejável da sociedade de consumo. A humanidade passou os últimos 100 anos preocupada com a produção, agora terá que conviver com os custos da despoluição.

A reciclagem é uma solução para minimizar o problema do lixo, mas nem sempre viável. Uma das soluções pode estar numa equação simples: quem gerar mais lixo terá que pagar mais por isso. Desta forma as pessoas não terão incentivos para produzir dejetos.

A questão do lixo gerado nas cidades é um dos grandes problemas da maioria dos municípios brasileiros. Os altos custos da implantação e manutenção dos sistemas de coleta e tratamento de lixo têm levado ao fracasso muitas tentativas de equacionamento. Como sempre, é a comunidade que vai sofrer os maiores impactos ambientais, produzidos pela falta de saneamento dos resíduos domésticos, hospitalares e industriais, com expressivo aumento de doenças. Uma 
tonelada de lixo ocupa até $6 \mathrm{~m}^{3}$ de volume espacial. Uma cidade pequena que coleta 50 toneladas por semana, ocuparia cerca de $300 \mathrm{~m}^{3}$ de volume espacial semanalmente, ou seja, volume suficiente para poluir vários ecossistemas, simultaneamente, ao final de um ano.

Os lixos favorecem o desenvolvimento de bactérias patogênicas e permitem proliferação de ratos e baratas (transmissores da doença) além de poluir diretamente a água e o ar pelo resíduo liquido e gasoso, após as chuvas.

Segundo OLIVEIRA \& PASQUAL (1998), um gerenciamento integrado de resíduos eficaz deve conter alguns ou todos os seguintes componentes: redução de resíduos (incluindo o re-uso dos produtos), reciclagem de material (incluindo compostagem), recuperação de energia por resíduo combustível e disposição final (aterros sanitários).

Além de condicionar o solo, o composto orgânico melhora características físicas do solo aumentado a capacidade de retenção de água e ar, devido a ação agregadora em solos com baixo teor de argila; aumenta teor de nutrientes, estabilizando o $\mathrm{PH}$ e melhorando o aproveitamento dos fertilizantes minerais; ativa a vida microbiana; favorece a presença de micro nutrientes; auxilia o desenvolvimento do sistema radicular, a recuperação de ares deterioradas, protege encostas em parques e jardins; aumenta o rendimento da adubação mineral de 30 a 70\% (Lindemberg, 1990 apud OLIVEIRA \& PASQUAL, 1998).

\section{Reciclagem de Plásticos}

Apesar de contarcomuma experiência acumulada de quase 30 anos, o reaproveitamento do plástico, no Brasil, ainda permanece como uma atividade incipiente. Mas a previsão para o futuro é diferente: altamente rentável e estratégica para a preservação ambiental, a reciclagem de resíduos plásticos deverá expandir-se e despontar ainda nessa década como mais uma atividade produtiva e de apóio a produção. A previsão otimista dos próprios recicladores e dos fabricantes de máquinas baseia-se no crescimento já verificado no setor. Cresce em todo país o número de pequenas empresas recicladoras e a demanda por informações técnicas é cada vez maior. Os apoios tecnológicos e incentivos fiscais àqueles que se aventuram na área são inexistentes, até o presente momento.

A matéria-prima a ser recuperada encontra-se nos mais variados locais e pode ser dividida em duas categorias: sucata comum e sucata industrial.

A sucata comum é aquela encontrada no lixo domestico e nos depósitos de lixo das prefeituras. O custo desse material é zero, pois está misturado ao lixo orgânico e se não for recuperado será aterrado junto com todo o lixo restante, causando poluição ao meio ambiente, pois o plástico, na melhor das hipóteses, demora cerca de 50 anos para decompor-se. 0 grande problema desse tipo de sucata é que como o plástico está misturado com vários outros materiais, torna-se difícil sua separação.

A sucata industrial é proveniente das indústrias que manufaturam artefatos plásticos, ou mesmo das indústrias que produzem plástico. Esse é um tipo de sucata limpa, pois além de não estar misturada a outros materiais, ainda há a possibilidade de saber exatamente qual material se está trabalhando. Existem dois tipos de sucata industriais: borras e aparas.

A borra é proveniente das maquinas sopradoras e extrusoras e pode ser obtida de várias maneiras.

Uma das maneiras de obter a borra é quando, no processo de sopro ou extrusão, acontece 
um problema no canhão da maquina ou cabeçote, e o plástico acumula-se formando uma borra. Nesse caso, a não ser que o material tenha sido queimado devido a um super aquecimento, uma sucata limpa.

Outra maneira de se encontrar borra é quando se troca o plástico que será extrusado ou soprado. Nesse caso, será necessário limpar a máquina para que o novo plástico não seja contaminado por aquele que estava sendo usado. Esse tipo de borra não é uma sucata limpa, já que ela foi contaminada com outro tipo de plástico no momento da limpeza da máquina.

A apara é um tipo de sucata proveniente principalmente das máquinas injetoras, podendo também ser produto de processos de prensagem, ou mesmo de sopro. Mas, qualquer que seja o processo que tenha gerado essa sucata, o resultado é bastante bom, pois salvo os casos de peças que tenham junções de dois tipos de plásticos diferentes, será bem fácil separa o material. A apara é uma sucata quase limpa.

Há ainda outro tipo de sucata industrial, mais difícil de ser encontrada, que está dividido em dois grupos: rejeitos e corpos de prova. Esses dois tipos de sucatas são encontrados nas indústrias que fabricam o plástico.

Os rejeitos são aqueles materiais que não atingiam as especificações do fabricante e não podem ser vendidos como matéria-prima da linha da indústria porque não atendem às especificações técnicas esperadas. Isso ocorre quando, por algum motivo, acontece um erro no processo de polimerização, aditivação ou pigmentação. Esse tipo de material pode ser considerado como sucata limpa.

Os corpos de prova representam um tipo bastante especial de sucata e não são encontrados em grande quantidade. Toda vez que se faz uma batelada de polimerização na indústria recolhe-se uma amostra do produto final que é submetida a testes para verificar que se está de acordo coma especificações. Essa sucata é, possivelmente, a mais limpa de todas.

\section{Contaminação}

Um dos problemas encontrados mais frequentemente na recuperação é a contaminação. Principais tipos de contaminação que os materiais plásticos podem apresentar:

- Contaminação por fusão: esse tipo de contaminação se dá quando, no caso da borra, o plástico foi usado para limpar o canhão de uma máquina e fundiu-se com resíduos de outros plásticos. Quando isso acontece, é necessário saber com que material se contaminou, pois é praticamente impossível a sua descontaminação através de dissolução fracionada por solventes para altos pesos moleculares. E também, além de ser um processo não muito satisfatório, é comercialmente inviável. A única saída nesse caso é saber se os plásticos que se fundiram possuem alguma afinidade, podendo então dar origem a um copolímero.

- Contaminação física: esse tipo de contaminação é de fácil solução, pois o material está somente misturado fisicamente com outro. O plástico, nesse caso, pode estar contaminado com o mesmo tipo, somente alterando a cor, ou por outro tipo de plástico. Quando se trata de um mesmo plástico no qual somente a cor difere, a separação deve ser manual, por processo de catação. Entretanto, se a contaminação se der por um material diferente é preciso conhecer as diferenças entre os dois materiais para escolher o método mais adequado de descontaminação. Por exemplo: dois plásticos de densidades diferentes podem ser separados usando um tanque de água, no qual o material mais denso irá depositar-se e o outro flutuar.

- Contaminação química: é quando temos um tipo de sucata que esteve em contato com algum 
produto que deixou vestígios. Por exemplo: frascos de desodorante, frascos de remédios, embalagens de produtos alimentícios, etc. A descontaminação será mais ou menos complicada, conforme o agente que causou a contaminação. Na maioria das vezes uma simples limpeza com jatos de água é suficiente. Caso seja necessário o uso de algum solvente para auxiliar a limpeza, é preciso usá-lo com muita cautela para que não haja mais contaminação ainda.

\section{Técnicas de Recuperação}

Existem duas técnicas básicas de recuperação. Uma delas é o uso comum a todos os termoplásticos e a outra restrita a apenas alguns, especialmente acrílico.

A primeira técnica baseia-se na propriedade de termoplasticidade dos polímeros e dividi-se em quatro fases: moagem, lavagem, extrusão e granulação.

Na moagem o material é levado ao moinho, a fim de ser fragmentado em partes menores de modo a facilitar o trabalho da extrusora. Em seguida o material é levado a um tanque e seco em uma centrifuga. Nesse ponto o material já está pronto para ser levado para a extrusora, onde irá fundir-se no canhão impulsionado pela rosca até chegar na tela do cabeçote onde será dividido em fios como espaguete. O material é então levado até uma banheira de resfriamento, seguindo depois para o picotador.

A segunda técnica serve mais para os materiais acrílicos. Esses polímeros têm uma propriedade muito interessante e particular, que é a de voltar ao estado de monômero após a polimerização, tornando esse tipo de material e excelente para recuperação, pois pode ser recuperado com $100 \%$ de suas características.

Essa técnica está baseada na destilação e, para tanto, faz-se o uso de um reator.

O material é moído e então colocado no reator onde é aquecido. Quando atinge uma temperatura próxima aos 100 C, o material entra em ebulição e sobe para coluna de resfriamento passando para o estado líquido. Pode, após, ser adicionado a um inibidor de polimerização, como a antraquinona, sendo conservado como monômero para futura polimerização, ou, então, ser polimerizado em placas, blocos, etc.

Nessa técnica, mesmo que o material contenha pigmentos ou aditivos, ele sairá limpo pois, durante a destilação esses agentes ficarão retidos no reator.

\section{Reciclagem do Material Plástico no Brasil}

O interesse pela reciclagem de plástico pode ser sentido durante a realização do seminário Plásticos: a indústria da reciclagem, realizado em dezembro de 1994, em São Paulo. Promovido pelo Instituto de Pesquisas Tecnológicas (IPT) e pelo Compromisso Empresarial para a Reciclagem (Cempre), o evento contou com a participação de representantes de empresas recicladoras, tecnólogos e fabricantes de máquinas, assim como empresários, sucateiros e ambientalistas, numa demonstração efetiva de que o tema demanda amplos debates.

Assunto para debate não falta. Aquilo que para os empresários é fonte de lucro, para os ambientalistas é motivo de preocupação. Dados fornecidos pela Limpurb, empresa de limpeza urbana da prefeitura de São Paulo, demonstram que somente a cidade de São Paulo com seus 
12 milhões de habitantes, produziu, em 1993, 14 mil toneladas de resíduos sólidos por dia, dos quais se estimam que 5 a 7\% (em peso) e cerca de 20\% (em volume) eram plásticos. Em São Paulo, a quantidade de plásticos lançada em lixões - aproximadamente 250 mil toneladas por ano - corresponderia, nesse caso, a produção de uma indústria petroquímica de segunda geração.

A maior parte dos plásticos encontrados no lixo é composta por embalagens flexíveis que, há cerca de três décadas, tem substituído o papelão, o vidro e o metal no acondicionamento de alimentos e produtos de higiene. Segundo a Associação Brasileira das Indústrias de Embalagens Plásticas Flexíveis (Abief), as embalagens representam cerca de $40 \%$ da média de 1,5 milhões de toneladas de termoplásticos produzidos anualmente no Brasil. 0 polietileno de baixa densidade (PEBD), que é a resina mais utilizada para embalagem de produtos, corresponde a $30 \%$ dos polímeros consumidos hoje no país.

Mesmo a reciclagem do plástico ainda não conseguiu a simpatia absoluta dos ambientalistas e ecólogos. $O$ processo utiliza grande quantidade de água que ao final estará contaminada. $\mathrm{O}$ que fazer com ela? As recicladoras, em geral pequenas empresas, alegam não poder arcar com os custos do tratamento da água e reivindicam incentivos fiscais e tecnológicos para tentar resolver a questão. A reutilização do plástico também requer normas e fiscalização. Já houve casos de resinas recicladas usadas na fabricação de utensílios domésticos e debrinquedos que estavam contaminadas com resíduos tóxicos e microorganismo.

Apesar de todas essas ressalvas e preocupações, a reciclagem, se não é a ideal, e a melhor solução que se tem no momento, pois concilia os interesses ambientais e empresariais.

\section{Motivação Econômica}

Os danos ambientais causados pelo lixo plástico por si só tornam a reciclagem justificável, mas deve-se acrescentar a eles um dado fundamental: plástico é petróleo e petróleo é dinheiro.

Dos plásticos reciclados no Brasil, cerca de $60 \%$ são constituídos de PEBD e PEAD, em razão de sua maior disponibilidade no mercado. Os $40 \%$ restantes são compostos pelo PVC, PS, e PP. Segundo o Cempre, no Brasil o maior mercado é o da reciclagem primária que consiste na regeneração de um único tipo de resina por vez. No caso da reciclagem secundaria processamento de polímeros misturados - já existem tecnologias disponíveis, mas o crescimento do setor depende de grandes investimentos. É o caso da madeira plástica fabricada pela Reciplast. Ainda não estão sendo aplicados no Brasil processos químicos para recuperar resinas plásticas, a chamada reciclagem terciária.

Atualmente apenas $15 \%$ dos produtos plásticos produzidos no país são feitos de resina reciclada. São em geral sacos de lixo, mangueiras para irrigação, conduítes para a construção civil, lonas para a agricultura, solados para calçados, caixas para transporte de carga e peças de automóveis. Vendidos a preços até $50 \%$ menores que os similares feitos com resina virgem, esses produtos apresentam boa qualidade e tem ajudado a desfazer a imagem negativa dos reciclados.

Apoiada no interesse econômico, na facilidade de execução e no apelo ecológico, a reciclagem tem potencial para crescer e deslanchar. Para que isso aconteça, falta desenvolver mais efetivamente a coleta seletiva do lixo e a separação do plástico, etapas que ainda estão à margem do processo na maioria das cidades. A maioria das empresas recuperadoras demplástico usa apenas resíduo industrial, que já é encontrado limpo e classificado, 
descartando os plásticos que vem com lixo domestico. A coleta, a seleção e a lavagem do material que vem do lixo urbano encarece a reciclagem e demanda uma estrutura que 0 reciclado não possui.

A coleta e a classificação do lixo plástico são os pontos de estrangulamento para o desenvolvimento da reciclagem no Brasil. Para o leigo, tudo é plástico. Basta coletar para vendê-lo. Ele não imagina as dificuldades para separar os tipos de plásticos. A cada dia surgem novas resinas plásticas que demandam métodos novos. Se não forem separados antes da moagem, os plásticos provocaram danos no equipamento e perda de qualidade do produto, inviabilizando o processo de reciclagem. Daí a necessidade da profissionalização da atividade de sucateiro.

Apesar das dificuldades, experiências de sucesso em coleta seletiva já têm sido realizadas no país. Em Porto Alegre, onde o Cempre realizou pesquisa, a coleta atinge $79 \%$ da população, mais de 1 milhão de pessoas e apresenta o menor custo.

Ainda que promissora e rentável, torna-se evidente que a reciclagem de plástico no Brasil necessita de um empurrão financeiro e tecnológico para dar seu salto para o futuro. A ajuda, opinam alguns recicladores, deveria vir na forma de diminuição da carga tributaria ou de linhas de financiamentos especiais para atividades que contribuam para a preservação ambienta, como a reciclagem do lixo. Na área tecnológica, é preciso financiar e incentivar pesquisas que busquem soluções para a reciclagem no país.

\section{METODOLOGIA DE TRABALHO}

A pesquisa foi planejada em etapas, onde os alunos de uma turma de 4á série do ensino básico do Colégio Madre Julia, no município de São Sepé - RS, executaram as seguintes tarefas: leitura dos seguintes textos: "Lixo e Reciclagem", " SOS - Salve o Planeta", Algumas dicas das "Trinta dicas para cuidar do Planeta" e "Lixo que não é Lixo - Vida de Papel".

Seguiu-se a interpretação dos textos e discussão entre os alunos sobre os temas expostos. Estes realizaram pesquisas sobre o assunto, em jornais, revistas e na internet, escreveram pequenos textos e realizaram debates com os colegas orientados pela professora.

A partir dos resíduos plásticos - garrafas pet - foi iniciado um trabalho de como reutilizá-las, através da confecção de bonecos ou fantoches, seguindo um roteiro baseado na história "Vida de Papel" (anexo 4).

Os bonecos foram confeccionados com garrafas pet, descartadas no lixo e cada aluno foi estimulado a escrever uma história para o seu personagem.

Inicialmente cada aluno apresentou seu personagem com sua história para os colegas da turma. Os textos foram reunidos num livro "VIDA DA GARRAFA PET" apresentado ao público em 16 de outubro de 2009 nas dependências do colégio.

\section{RESULTADOS E DISCUSSÃO}

Os textos utilizados fazem parte do material didático do colégio, estando inseridos na apostila do SER (Sistema de Ensino SER, reúne livros didáticos e paradidáticos das Editoras Ática e Scipione à informação e qualidade do Grupo Abril).

Os trabalhos de leitura foram iniciados no dia 01 de junho de 2009, com os 28 alunos da 4a série do ensino básico do colégio. 
Após cada leitura deram-se inicio aos debates entre os alunos sobre o conteúdo apresentado e muitos foram atrás de maiores informações sobre o assunto, em jornais revistas e na internet.

Estas informações foram apresentadas em aulas seguidas de novos debates esclarecedores sobre os assuntos em debate.

Os quatro textos trataram direta ou indiretamente sobre o comportamento humano, ocorrente no dia a dia, no descarte de matérias e, esta foi à pauta principal para o trabalho dos alunos: a sensibilização do quanto as ações e comportamento diário podem influenciar no bem-estar do meio em que se vive.

O último texto " Lixo que não é lixo - Vida de Papel" motivou os alunos, para como usar os materiais postos à disposição dos mesmos, considerando os ensinamentos constante no texto estudado e discutido. A partir desta atividade surgiu a idéia de se escrever um livro "Vida da garrafa pet".

Os alunos construíram fantoches a partir de garrafas pet descartadas e iniciaram a escrita de um texto (história) para o seu personagem.

Cada aluno desenhou seu personagem no papel e começou a construí-lo com garrafa pet. A construção do seu personagem levou algumas semanas, e os bonecos de uma maneira geral com muita criatividade: gato, cachorro, porco, barco, borboleta, vaso, flores, etc.

Depois da confecção do fantoche, cada aluno passou a criar a história do seu personagem. Após alguns dias a história foi concluída e todos ficaram satisfeitos com seu trabalho intelectual (a história do seu personagem).

As histórias foram inicialmente apresentadas aos colegas junto com a exposição dos personagens. Utilizando o laboratório de informática, digitaram os textos.

O livro com os textos dos 28 alunos foi apresentado ao público no dia dezesseis de outubro com o título - VIDA DA GARRAFA PET - contando as 28 histórias criadas pelos alunos.

As leituras, seguidas pelas interpretações e debates, motivaram os alunos a modificarem seu comportamento cotidiano, em relação aos materiais descartáveis que antes eram simplesmente jogados no lixo e agora, muitos destes materiais passaram a ser utilizados sob outra forma, diminuindo os desperdícios, a contaminação e a poluição ambiental.

A melhoria da qualidade de vida resultante destas pequenas mudanças de comportamento e de atitudes, através da reciclagem, indicou que a transmissão do conhecimento, de uma forma criativa (Educação ambiental), pode ajudar a cumprir o arti 255, da Constituição Federal, quando trata da questão ambiental.

\section{CONSIDERAÇÕES FINAIS}

Durante o período de trabalho com a turma de 4 a série do ensino básico do Colégio Madre Julia, no município de São Sepé - RS foi observado que, em geral, as crianças estiveram muito dispostas a realizar todas as atividades propostas.

No trabalho com os textos, os alunos tiveram interesse em ouvir e entendê-los, assim como igualmente se interessaram em perguntar sobre o assunto. Os questionamentos dos alunos e interesses pela preservação da natureza foram muito importantes.

Os alunos foram sensibilizados sobre o que se passa em nosso dia-a-dia, percebendo práticas que melhoram o meio em que vivemos. Atentos ao reflexo de suas ações na sociedade e na natureza receberam seu livro, fruto de sua imaginação, como contribuição para uma boa leitura. 


\section{REFERÊNCIAS BIBLIOGRÁFICAS}

Brasil. Constituição (1988). Constituição: República Federativa do Brasil. Porto Alegre: Ordem dos Advogados do Brasil, Estado do Rio Grande do Sul, 1988.

Brasil. Lei Federal no. 6.938 de 31 de Agosto de 1981. IN: Legislação Brasileira do Meio Ambiente. Organizado por Rogério Rocco. RJ: DP\&A, 2002.

Brasil. Lei Federal n. 9.795 de 27 de abril de 1999. Política Nacional de Educação Ambiental. Brasília.

CAPRA, F. A Teia da Vida: Uma Nova Compreensão Científica dos Sistemas Vivos. São Paulo: Cultrix e Amana-Key, 1996.

CARVALHO, I. C. de M. A Invenção Ecológica: narrativas e trajetórias da educação ambiental no Brasil. Porto Alegre: UFRGS, 2001.

DIAS, G. F. Educação ambiental - princípios e práticas. 2ª . ed. São Paulo: Gaia, 1993.

DUTRA, A.L. Lixo: problemas e soluções. Porto Alegre Prefeitura Municipal de Porto Alegre, Departamento Municipal de Limpeza Urbana, 1991.

LONDERO, L. K.. MUSEU E TEATRO COMO PRÁTICAS DE EDUCAÇÃO AMBIENTAL. Santa Maria, 2007. Monografia (especialização) -Universidade Federal de Santa Maria, 2007.

MEC, Ministério da Educação, http://portal.mec.gov.br/, acesso em: 22 out. 2008.

MEDINA, N. M. SANTOS, E. da C. Educação Ambiental: uma metodologia participativa de formação. Petrópolis: Vozes, 1999.

MMA, Ministério do Meio Ambiente, http://www.mma.gov.br/, acesso em: 22 out. 2008.

OLIVEIRA, S \& PASQUAL, A Gestão dos resíduos sólidos urbanos na microrregião Serra Botucatu caracterização física dos resíduos sólidos domésticos de Botucatu/SP. In: Energia na agricultura, vol. 13 no 2 . São Paulo, 1998.

PELICIONI, A. F. Subsídios Teóricos e Práticos Para a Educação Ambiental na Escola. S.Paulo: Debates Socioambientais, 1998.

PNEA, Política Nacional de Educação Ambiental, http://www.mma.gov.br/, acesso em: 22 out. 2008, 1999.

REIGOTA, M. Meio Ambiente e Representação Social. São Paulo: Cortez, 1995 (Questões da nossa época n.41).

ROCHA, J. S. M. da. Educação Ambiental Técnica Para os Ensinos Fundamental, Médio e Superior. 2a ed. Santa Maria: Imprensa Universitária, 1999.

ROTH, B. W. Tópicos em educação ambiental: recortes didáticos sobre o meio ambiente. Santa Maria: Pallotti, 1996.

SILVA, P.M. da. A poluição. São Paulo: DIFEL - Difusão Editorial S.A., 1975. 119p.

SILVA, G.E. da. Direito Ambiental Internacional: meio ambiente, desenvolvimento sustentável e os desafios da nova ordem mundial. Rio de Janeiro: Biblioteca Estácio de Sá, 1995. 